pated in the first survey. Of the 13 respondents, 11 of whom had returned the previous survey, only two commented that population based data could be produced, while another two could supply hospital based datasets. The obstacles encountered by regional coordinators in providing data for 1993 and 1995 are given in the table.

\section{Comment}

Obtaining comparable national data on births from NHS sources is difficult for even the most basic items, and the situation is worsening rapidly. Undoubtedly, the loss of the information gathering function of former regional health authorities has had an important impact. However, a few coordinators mentioned a new factor: contributing to national data had a low priority. They blamed purchasers and the Department of Health, but many doctors also show little interest. ${ }^{4}$

If we are to have national data on births, risks and benefits will have to be identified for the NHS Executive, the Department of Health, purchasers, doctors, midwives, and data entry clerks. Once these groups are convinced of the importance of this work, a coalition of committed participants could be formed to resolve the difficulties illustrated by this study.

A recent study showed that only $60 \%$ of midwives could retrieve useful information from local maternity systems, while those working regionally and nationally find data almost unobtainable. ${ }^{5}$ With such an imbalance between the high effort to input data and the low utility of output, is collecting dozens of details for every birth worthwhile?

Many thanks to Alison Macfarlane (National Perinatal Epidemiology Unit), Lesz Lancucki (Department of Health) and the staff of the secretariat of the confidential inquiry into stillbirths and deaths in infancy, in particular Verena Wallace, Juliet McEachran, and past directors Ralph Settatree and Rosalind Stanwell Smith. A special thanks to all the regional coordinators who put in extra time and effort to make this study possible.

A full report is available from the Confidential Enquiry into Stillbirths and Deaths in Infancy Secretariat, Chiltern Court, 188 Baker Street, London NW1 5SD.

Funding: Confidential Enquiry into Stillbirths and Deaths in Infancy Secretariat.

Conflict of interest: None.

1 Macfarlane A, Mugford M, Johnson A, Garcia J. Counting the changes in childbirth: trends and gaps in national statistics. Oxford: National Perinatal Epidemiology Unit, 1995

2 Middle C, Macfarlane A. Labour and delivery in 'normal' primiparous women-analysis of routine collected data. Report for the Clinical Standards Advisory Group. Oxford: National Perinatal Epidemiology Unit, 1995.

3 Department of Health. Annual report on confidential enquiries into stillbirths and deaths in infancy 1994. London: HMSO, 1996.

4 NHS Executive. HISS management of change-removing the barriers to clinicians' acceptance of HISS. A study of the communication links in an obstetric unit. Winchester: Hospital Information Support Systems, 1996 (Report D4039.)

5 Dobson P. Survey of computerised midwifery information systems. $\mathrm{Br}$ Midwifery 1995;3:487-92.

(Accepted 21 November 1997)

\title{
Abortion rates in England in 1995: comparative study of data from district health authorities
}

\author{
Veena Soni Raleigh
}

British developmental aid for developing countries prioritises greater reproductive choice for women through improved contraceptive services. But is enough being done in the United Kingdom to reduce unwanted pregnancies? I studied lifetime fertility, abortion rates, and the proportion of pregnancies resulting in induced abortion in 105 district health authorities in England.

\section{Subjects, methods, and results}

I analysed data on births and legal abortions during 1995 by district health authority as compiled by the Office for National Statistics. Total period fertility rates are a conventional measure of the mean number of live births that a woman would have if she experienced the current age specific fertility rates throughout her childbearing years. These rates were calculated by summing the 5 year age specific fertility rates at ages 15-49 and multiplying by 5 . Total period abortion rates were similarly calculated. The total period pregnancy rate is the sum of the total period abortion rate and total period fertility rate. Stillbirths and spontaneous abortions were excluded.

In 1995, 147851 abortions occurred among women resident in England compared with 613257

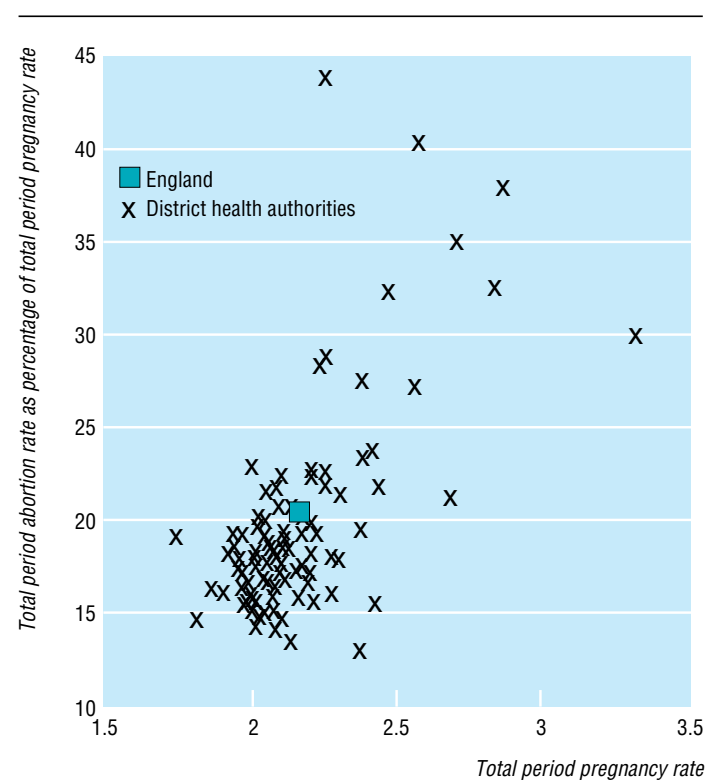

Total period pregnancy rates and total period abortion rates as percentages of total period pregnancy rates in England overall and by district health authority, 1995 
live births, a ratio of 1:4. This was equivalent to a total period fertility rate of 1.72 births (less than the population replacement level of 2.2) and a total period abortion rate of 0.44 abortions over a woman's lifetime. Total period fertility rates showed a 1.8 -fold variation (1.26 to 2.32) and total period abortion rates a 4.2-fold variation ( 0.26 to 1.09 ) between district health authorities. Total period abortion rates were highest in London and possibly showed some movement between districts of women seeking a termination.

On the basis of rates in 1995, a woman in England will have an average of 2.16 pregnancies during her lifetime, of which $0.44(20.4 \%)$ will result in an abortion. Interdistrict variation in the mean number of pregnancies ranged from 1.74 to 3.31 , with $13 \%-44 \%$ being aborted (figure). The comparative contribution of fertility and abortion to total period pregnancy rate varied regionally-for example, whereas women in Bradford and Croydon had a similar number of pregnancies (2.37), the ratio of live births to abortions was 2.06:0.31 and 1.72:0.66 respectively. Both total period pregnancy rate (3.31) and total period fertility rate (2.32) were highest in East London and the City District Health Authority, which also had one of the highest total period abortion rates nationally $(0.99)$. In contrast, Camden and Islington had the third lowest total period fertility rate nationally (1.53) and the second highest total period abortion rate (1.04).

About 20\% of abortions occur in women under 20 , among whom $40 \%$ of pregnancies are terminated; the proportion in parts of London and the southeast is half to two thirds.

\section{Comment}

One in five pregnancies in England results in a termination, giving a mean lifetime abortion rate of 0.44 per woman, which is higher than a decade ago. ${ }^{1}$ Most women having abortions are young (under 30), single, and childless. ${ }^{2}$ More women (26.9\%) are having repeat abortions..$^{23}$ Not practising safe sexual intercourse is associated with abortion, testing for HIV, and treatment for sexually transmitted diseases. ${ }^{4}$ Contraceptive use is associated with social class, and abortion rates rise with deprivation. ${ }^{4}$ These factors indicate the need and potential for targeted, preventive interventions.

Globally, illegal abortions are an important cause of morbidity and mortality among women of reproductive age, particularly in developing countries. ${ }^{5}$ High fertility and abortion rates in developing countries can be readily explained, but high abortion rates in affluent populations of low fertility with ready access to contraception are less easy to rationalise. Women in all societies need access to safe, legal abortion services. With the Abortion Act 1967, the United Kingdom led other European countries in reforming abortion legislation. As in the Netherlands, there is a need to target the causes of unwanted pregnancy through more effective education and contraceptive services. This will also reduce the costs of abortion and improve sexual health.

The concepts used in this paper were derived from Population Health Outcome Indicators: a Feasibility Study and Public Health Common Data Set, both published by the Department of Health.

Funding: None.

Conflict of interest: None.

1 Clarke M. Fertility and legal abortion in England and Wales: performance indicators for family planning services. BMJ 1988;297:832-3.

2 Office for National Statistics. Abortion statistics. HMSO: London, 1996. (Series AB No 21.)

3 Botting B. Trends in abortion. Popul Trends 1991;64:19-29.

4 Johnson AM, Wadsworth J, Wellings K, Field J. Sexual attitudes and lifestyles. Oxford: Blackwell Scientific, 1994.

5 Kulczycki A, Potts M, Rosenfield A. Abortion and fertility regulation. Lancet 1996;347:1663-8.

(Accepted 16 December 1997)

\title{
Embryonic abnormalities at medical termination of pregnancy with mifepristone and misoprostol during first trimester: observational study
}

\author{
G Blanch, S Quenby, E S Ballantyne, C M Gosden, J P Neilson, K Holland
}

Department of Obstetrics and Gynaecology, University of Liverpool, Liverpool L69 3BX G Blanch, senior registrar S Quenby, lecturer E S Ballantyne, research fellow C M Gosden, professor of medical genetics

J P Neilson, professor of obstetric and gynaecology

continued over

BMJ 1998;316:1712-3
Accurate data on the incidence and nature of embryonic and fetal abnormality during the first trimester and of non-viable pregnancy are needed so that women who have experienced miscarriages can be counselled, and abortion and early prenatal diagnostic services can be improved. New medical techniques for abortion in the first trimester ${ }^{1}$ enabled us to collect and analyse data on undamaged first trimester pregnancies.

\section{Subjects, methods, and results}

Between November 1994 and August 1996, 506 healthy women chose medical termination of their pregnancy before nine weeks' gestation in the dedicated day care abortion unit of the Liverpool Women's Hospital. Women attended twice (firstly for oral mifepristone and then for oral misoprostol), and most aborted after receiving misoprostol and while still in the unit. Altogether, 293 passed products of conception in the day care unit (all within six hours of receiving misoprostol); 223 of these had given informed consent to study of the tissues. Women who were ineligible for study included 76 who had passed products of conception after receiving mifepristone but before readmission to the day care unit for misoprostol and a further 127 who passed products after discharge from the day care abortion unit. In only 10 women did the medical termination of pregnancy fail.

All specimens were examined macroscopically on the day of termination and fixed in 4\% paraformaldehyde. The embryos that appeared structurally abnormal on macroscopic examination were further examined histologically. Strict criteria were used to distinguish structural abnormality from traumatic damage. Agreement among three investigators (GB, $\mathrm{SQ}$, and $\mathrm{ESB}$ ) was required before a classification was 